\title{
THERMAL STABILITY OF TI/NI MULTILAYER THIN FILMS
}

\author{
${ }^{1}$ Richard VÁCLAVIK, ${ }^{1}$ Lukáš ZÁBRANSKÝ, ${ }^{1}$ Pavel SOUČEK, ${ }^{1}$ Pavel SŤAHEL, ${ }^{2}$ Jiří BURŠíK, \\ ${ }^{3}$ Tomáš FOŘT, ${ }^{1}$ Vilma BURŠíKOVÁ \\ ${ }^{1}$ Department of Physical Electronics, Faculty of Science, Masaryk University, Brno, Czech Republic, EU, \\ richard.vaclavik@mail.muni.cz \\ 2Institute of Physics of Materials, Czech Academy of Sciences, Brno, Czech Republic, EU, bursik@ipm.cz \\ 3Institute of Scientific Instruments, Czech Academy of Sciences, Brno, Czech Republic, EU, fortt@isibrno.cz
}

https://doi.org/10.37904/nanocon.2020.3776

\begin{abstract}
In this work, thermal stability and mechanical properties of $\mathrm{Ti} / \mathrm{Ni}$ multilayer thin films were studied. The multilayer thin films were synthesised by alternately depositing $\mathrm{Ti}$ and $\mathrm{Ni}$ layers using magnetron sputtering. The thickness of constituent layers of Ti and Ni varied from $1.7 \mathrm{~nm}$ to $10 \mathrm{~nm}$, and one coating was deposited by simultaneous sputtering of both targets. Single crystalline silicon was used as a substrate. The effects of thermal treatment on the mechanical properties were studied using nanoindentation and discussed in relation to microstructure evaluated by $\mathrm{X}$-ray diffraction. Annealing was carried out under low-pressure conditions for 2 hours in the range of $100-800^{\circ} \mathrm{C}$.
\end{abstract}

Keywords: Ti/Ni, multilayers, magnetron sputtering, nanoindentation, annealing

\section{INTRODUCTION}

By continually increasing demands and needs of humankind, science and research have reached a state where standard monolithic materials are no longer sufficient. Thanks to this, materials with a complex and advanced structure are currently being studied intensively.

One of the new trends in the thin films synthesised by plasma deposition is controlling the properties of coatings, for example, by alternating layers of various materials at the nanoscale and achieve functions that none of the original components has. In this way, it is possible to create a multilayered thin film with the option to choose the thickness of constituent layers, the ratio of layers thicknesses, the number of constituent layers, etc $[1,2]$.

$\mathrm{Ti} / \mathrm{Ni}$ multilayered thin films are one of the complex structures with superior functional properties (e.g. electric, magnetic and optical). These multilayered systems can be used to form TiNi shape memory alloys (SMA) which exhibit two closely related properties: shape memory effect (SME) and superelasticity (SE). These effects are caused by the martensitic transformation from a simple cubic structure (austenitic, phase B2) to a monoclinic crystalline structure (martensite, phase B19'), whereas this phase transformation is reversible and instantaneous. The transformation can be achieved by annealing or by applying stress [3,4]. Thanks to the remarkable SE and SME effects, TiNi SMA can be found in a wide range of fields such as medical, aeronautic, electric, telecommunication or as sensors and actuators in MEMS [4-8].

In this work, annealing was chosen to ensure the transformation. In the case of this approach, the uniformity of layers thicknesses on the nanoscale is crucial [9]. Moreover, for applications in MEMS, it is necessary to produce TiNi thin films with a thickness of several $\mu \mathrm{m}$. For these reasons, magnetron sputtering is one of the most common deposition techniques to synthesise multilayer thin films with low total thicknesses and adequate uniformity. For the fabrication of Ti/Ni multilayer films, a dual-head sputtering system with $\mathrm{Ti}$ and Ni targets can 
be utilised and periodically turned the power on and off ensures alternating nanolayers of pure $\mathrm{Ti}$ and $\mathrm{Ni}$. Afterwards, this multilayered system can be converted into the TiNi alloy thin film through solid state amorphisation by using a heat treatment. A significant advantage of magnetron sputtering over other deposition techniques used for multilayer thin films as e-beam evaporation, pulsed laser deposition or accumulative roll bonding, is an option of easily scalable resulting structure of multilayer by choosing deposition properties [10].

In this work, we have been mainly focused on thermal stability and development of mechanical properties with annealing of Ti/Ni multilayers prepared by dual-head magnetron sputtering of Ti and Ni targets. Annealed thin films composed of nanolayers with different thicknesses underwent nanoindentation tests, and results were discussed in relation to microstructure obtained by X-ray diffraction.

\section{EXPERIMENTAL}

$\mathrm{Ti} / \mathrm{Ni}$ multilayers were synthesised by dual-head magnetron sputtering in an argon atmosphere. To ensure multilayer structure, the power on titanium and nickel targets was periodically turned on and off depending on which layer was currently depositing. Single crystalline silicon was used as substrates and before the deposition they were etched by ion bombardment for 5 minutes. During the deposition, the negative floating potential was applied on a substrate holder and to achieve sufficient spatial homogeneity, the substrate was rotating. By deposition of one-layered coatings of $\mathrm{Ti}$ and $\mathrm{Ni}$, their deposition rates were found to be $0.75 \mathrm{~nm} / \mathrm{s}$ and $1.52 \mathrm{~nm} / \mathrm{s}$, respectively. The desired thickness of an individual layer $h$ was programmed by the variation of deposition time. The deposition conditions as applied power on targets, deposition pressure and substrate rotation speed for each multilayer design are listed in Table 1. The first presented coating $h=0 \mathrm{~nm}$ is prepared by simultaneous sputtering of both targets and therefore does not exhibits multilayered microstructure.

Table 1 Summary of deposition conditions of all Ti/Ni multilayered coatings

\begin{tabular}{|c|c|c|c|c|c|}
\hline $\boldsymbol{h}(\mathbf{n m})$ & $\begin{array}{c}\text { Overall thickness } \\
(\mathbf{n m})\end{array}$ & $\begin{array}{c}\text { Power on Ti } \\
\text { target (W) }\end{array}$ & $\begin{array}{c}\text { Power on Ni } \\
\text { target (W) }\end{array}$ & $\begin{array}{c}\text { Deposition } \\
\text { pressure (Pa) }\end{array}$ & Rotation (rpm) \\
\hline 0 & 500 & 350 & 350 & 0.30 & 3.0 \\
\hline 1.7 & 1190 & 300 & 300 & 0.16 & 4.8 \\
\hline 2.5 & 1000 & 300 & 300 & 0.16 & 4.8 \\
\hline 5.0 & 1000 & 300 & 200 & 0.16 & 4.8 \\
\hline 10 & 500 & 350 & 350 & 0.30 & 3.0 \\
\hline
\end{tabular}

After the deposition, one sample from each layering underwent a series of annealing in thermal desorption spectroscopy chamber from 50 to $800^{\circ} \mathrm{C}$. For each annealing, the constant temperature was kept for 2 hours.

One of the analytical methods utilised to study the effect of annealing was the depth-sensing nanoindentation performed on Hysitron T1950 Triboindenter equipped with a Berkovich tip. To determine the indentation hardness $H$ and the reduced elastic modulus $E_{r}$, nanoscale measuring head was used. This head allows measure in the load range from $50 \mathrm{nN}$ up to $11 \mathrm{mN}$ with a resolution of $1 \mathrm{nN}$. Several quasistatic tests with 20 segments of partial unloading were performed in load control regime. As it is shown in Figure 1a), each segment consists of three parts: loading, hold and unloading, and each part lasted 2 seconds. The result of such a loading function can be load-displacement curve plotted in Figure 1b), where every partial load segment can be evaluated according to the standard procedure proposed by Oliver and Pharr [11]. Thanks to that, the depth profile of hardness and modulus can be obtained by this approach. Example of such depth profiles are plotted in Figure 1c). In this work, single measurement consists of 16 load-displacement curves whose depth profiles were averaged and standard deviations were calculated. Values of the hardness and the 
reduced elastic modulus in the smallest common depth (negligible substrate influence) were used to compare samples and annealing temperatures.
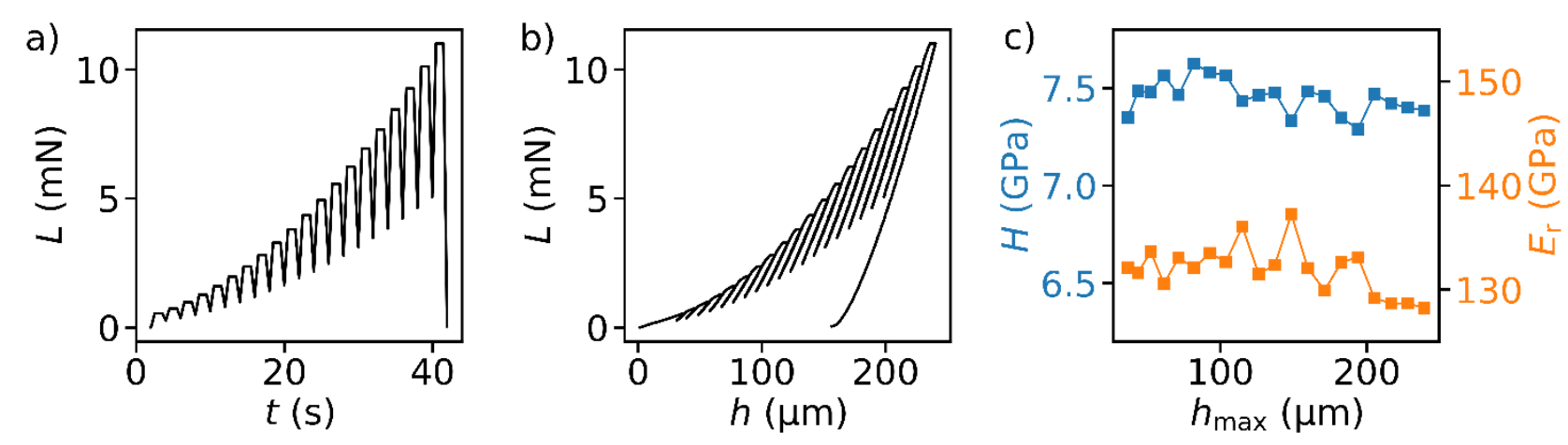

Figure 1 Quasistatic partial unload test: a) load function, b) load-displacement curve, c) hardness and reduced elastic modulus as a function of maximum depth per segment

In order to correlate the hardness and elastic modulus evolution with microstructural information, X-ray diffraction (XRD) was utilised for the phase identification. XRD experiments were performed in Rigaku Smartlab X-ray diffractometer using $\mathrm{Cu}$ Ka radiation with a wavelength of $0.15418 \mathrm{~nm}$ with a grazing angle of incidence configuration.

\section{RESULTS AND DISCUSSION}

The evolution of the hardness as a function of annealing temperature is plotted in Figure 2 for each studied multilayer. The increase of hardness of as-deposited multilayers with the increasing layer thickness in the used range was already reported in our previous study [12] and interpreted as an interface crossing of single dislocations [13,14]. After the first set of annealing at $100^{\circ} \mathrm{C}$, differences between hardness values of coatings get smaller even almost equalised at $200{ }^{\circ} \mathrm{C}$, what can be caused by alloying. With further increasing temperature, differences become more significant.

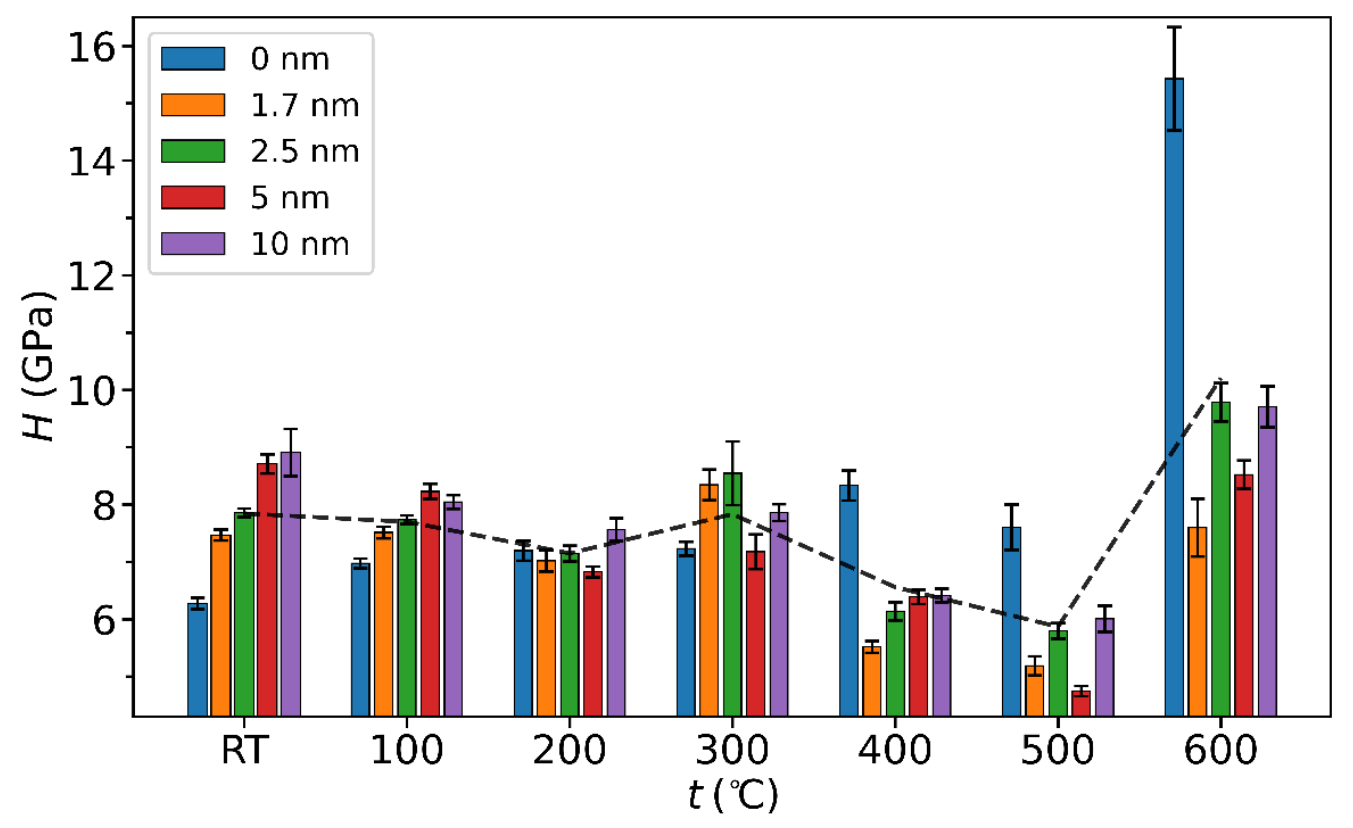

Figure 2 Development of hardness as a function of temperature for synthetised multilayers and one nonmultilayer coating labelled as $h=0 \mathrm{~nm}$ 
The average hardness for all coating and a specific temperature, marked by the dashed line, is continuously decreasing until $500{ }^{\circ} \mathrm{C}$, except for annealing temperature $300{ }^{\circ} \mathrm{C}$. At $600{ }^{\circ} \mathrm{C}$ hardness of multilayers significantly increased, and even more, a rapid increase occurred for non-multilayered coating $(\mathrm{h}=0 \mathrm{~nm})$ up to $15 \mathrm{GPa}$, which is more than twice as high as for the as-deposited coating. After annealing with even higher temperature, the coating has delaminated from the substrate or the coating has entirely desorbed. Substantial raise of hardness in the case of non-multilayer was not caused by higher substrate hardness, because the desorption was not observed even after annealing at $800^{\circ} \mathrm{C}$.

Reduced elastic modulus as a function of temperature was plotted in Figure 3 in the same way as for hardness evaluation. From room temperature (RT) to annealing temperature $200{ }^{\circ} \mathrm{C}$, order of reduced elastic modulus of multilayers was kept the same - maximum $E_{\mathrm{r}}$ for $h=5 \mathrm{~nm}$ and minimum $E_{\mathrm{r}}$ for $h=1.7 \mathrm{~nm}$. Dashed line indicating reduced elastic modulus for all coating and the specific temperature has a very similar development as in the same graph plotted for hardness. The reduced elastic modulus is gradually decreasing until $500{ }^{\circ} \mathrm{C}$, except for annealing temperature $300{ }^{\circ} \mathrm{C}$, where the obtained value is slightly higher. After annealing at $600{ }^{\circ} \mathrm{C}$, the reduced elastic modulus of multilayers increased but only a little. More significant influence of annealing temperature on the reduced elastic modulus was found in the case of multilayer with $h=1.7 \mathrm{~nm}$. In this case the reduced elastic modulus decreased $\sim 1.4$ times at $500{ }^{\circ} \mathrm{C}$ in comparison with as-deposited multilayer. The significant influence of annealing was found for non-multilayer coating as well. In contrast to the as-deposited coating, after annealing to $600{ }^{\circ} \mathrm{C}$, reduced elastic modulus increased $\sim 1.3$ times and was much higher than for multilayers.

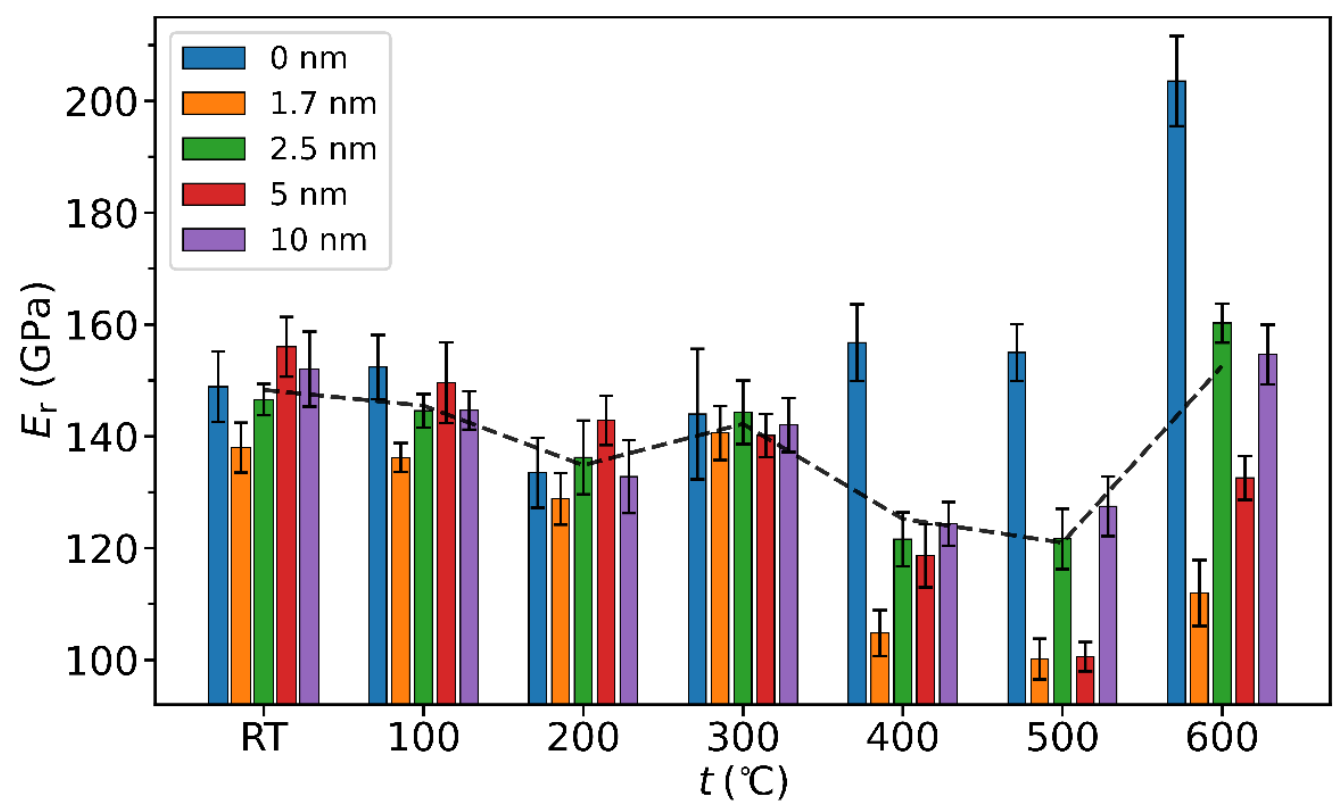

Figure 3 Development of reduced elastic modulus as a function of temperature for synthetised multilayers and one non-multilayer coating labelled as $h=0 \mathrm{~nm}$

For both coatings where significant influence of annealing was found, XRD measurements were performed in the range RT-500 ${ }^{\circ} \mathrm{C}$. The XRD diffractograms presented in Figure 4a) for $h=1.7 \mathrm{~nm}$ and in Figure $4 \mathrm{~b}$ ) for $h=0 \mathrm{~nm}$ exhibiting polycrystalline microstructure. The microstructure is composed of hexagonal (hcp) Ti, cubic (fcc) Ni grains and Ti-Ni intermetallic grains which emerged at higher annealing temperatures.

In the multilayer with $h=1.7 \mathrm{~nm}, \mathrm{Ni}(111)$ stays as the strongest peak with increasing annealing temperature from room temperature until $300{ }^{\circ} \mathrm{C}$. In this temperature range, the intensity of $\mathrm{Ti}(002)$ peak is decreasing, and this peak completely disappeared at $400{ }^{\circ} \mathrm{C}$. Other notably lower peaks $\mathrm{Ti}(110), \mathrm{Ti}(004)$ and $\mathrm{Ni}(222)$ disappeared as well. At this temperature, two new peaks corresponding to Ti-Ni intermetallic phase were 
detected, what is corroborated by previous works [15-17]. Shifted $\mathrm{Ni}$ (111) peak could contribute to the intensity of peak labelled as $\mathrm{TiNi}_{3}$ (004). The disappearance of individual $\mathrm{Ti}$ and $\mathrm{Ni}$ peaks indicates possible disintegration of the layers and the formation of fully intermixed and alloyed structure. These phenomena can be the cause of a drop in hardness and reduced elastic modulus development. In the coating with nonmultilayer structure, new intermetallic peaks did not emerge after higher annealing temperature, but they could contribute to the intensity of $\mathrm{Ni}$ (111) peak. This is highly probable due to a much easier way to form the alloyed structure from the non-multilayer structure. In this coating, noticeable shifting of the dominant peak is observed what can be caused by induced residual stress or by diffusion of atoms of one layer into another layer. Emerging and disappearing of $\mathrm{Ti}(010)$ and $\mathrm{Ti}(100)$ peaks is not clear yet, but more detailed investigations on this topic will be executed.
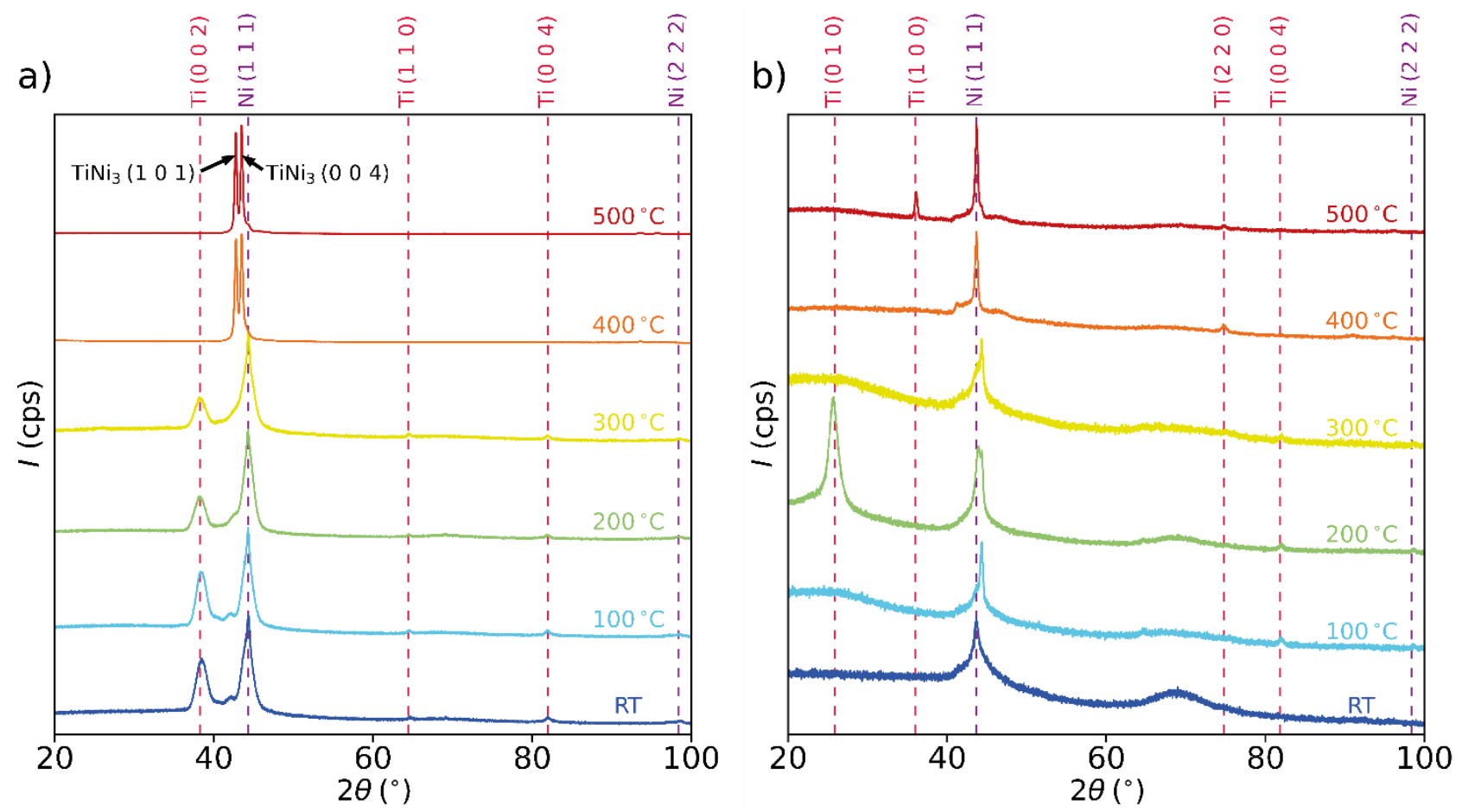

Figure 4 Diffraction patterns for Ti/Ni a) multilayer with individual layer thickness $h=1.7 \mathrm{~nm}$, b) non-multilayer coating labelled as $h=0 \mathrm{~nm}$

\section{CONCLUSION}

Several Ti/Ni multilayers synthesised by magnetron sputtering with different individual thicknesses of Ti and $\mathrm{Ni}$ layers were annealed. The main aim was to study the temperature dependence of their mechanical properties and to find a correlation with microstructural information. Based on the nanoindentation results, it was found out that hardness and reduced elastic modulus is decreasing with increasing annealing temperature until $500{ }^{\circ} \mathrm{C}$. After annealing to $600{ }^{\circ} \mathrm{C}$, both hardness and reduced elastic modulus increased especially in the non-multilayer coating (hardness of annealed at $600{ }^{\circ} \mathrm{C}$ is $\sim 2.5 \mathrm{x}$ higher than for as-deposited). After annealing at even higher temperature, coating has delaminated from the substrate or entirely desorbed. From the XRD results, it was concluded that all synthesised coatings have polycrystalline microstructure, which is becoming intermix and alloy after annealing at $\sim 400{ }^{\circ} \mathrm{C}$. The XRD patterns were described, and different phenomena were explained, and correlation with mechanical properties was proposed. 


\section{ACKNOWLEDGEMENTS}

The present work was supported by the Czech Science Foundation under project GACR 20-11321S, by the Ministry of Education, Youth and Sports of the Czech Republic under project NPU (LO1411).

\section{REFERENCES}

[1] VERESCHAKA, A.A., GRIGORIEV, S.N., SITNIKOV, N.N., OGANYAN, G.V., BATAKO, A. Working efficiency of cutting tools with multilayer nano-structured Ti-TiCN-(Ti,Al)CN and Ti-TiCN-(Ti,Al,Cr)CN coatings: Analysis of cutting properties, wear mechanism and diffusion processes. Surface \& Coatings Technology. 2017, vol. 332, 198-213.

[2] ANTONOV, M., HUSSAINOVA, I., SERGEJEV, F., KULU, P., GREGOR, A. Assessment of gradient and nanogradient PVD coatings behaviour under erosive, abrasive and impact wear conditions. Wear. 2009, vol. 267, 898-906.

[3] MIYAZAKI, S., FU, Y.Q., HUANG, W.M. Thin film shape memory alloys: fundamentals and device applications. New York: Cambridge University Press, 2009.

[4] PAN, G., CAO, Z., WEI, M., XU, L., SHI, J., MENG, X. Superelasticity of TiNi thin films induced by cyclic nanoindentation deformation at nanoscale. Materials Science and Engineering: A. 2014, vol. 600, pp. 8-11.

[5] YAMAUCHI, K., OHKATA, I., TSUCHIYA, K., MIYAZAKI S. Shape memory and superelastic alloys: technologies and applications. Philadelphia, PA: Woodhead Publishing, 2011.

[6] CHOUDHARY, N., KAUR, D. Shape memory alloy thin films and heterostructures for MEMS applications: A review. Sensors and Actuators A: Physical. 2016, 242, 162-181.

[7] YONEYAMA, T., MIYAZAKI, S. Shape memory alloys for biomedical applications. Cambridge, England: Woodhead Publishing, 2009.

[8] JANI, J.M., LEARY, M., SUBIC, A., GIBSON, M.A. A review of shape memory alloy research, applications and opportunities. Materials \& Design. 2014, vol. 56, 1078-1113.

[9] FU, Y., DU, H., HUANG, W., ZHANG, S., HU, M. TiNi-based thin films in MEMS applications: a review. Sensors and Actuators A: Physical. 2004, vol. 112, 395-408.

[10] CHO, H., KIM, H.Y., MIYAZAKI, S. Fabrication and characterization of Ti-Ni shape memory thin film using Ti/Ni multilayer technique. Science and Technology of Advanced Materials. 2005, vol. 6, pp. 678-683

[11] OLIVER, W.C., PHARR, G.M. Measurement of hardness and elastic modulus by instrumented indentation: Advances in understanding and refinements to methodology. Journal of Materials Research. 2004, vol. 19, pp. 320.

[12] ZÁBRANSKÝ, L., VÁCLAVIK, R., PŘIBYL, R., ŽENÍŠEK, J., SOUČEK, P., BURŠíK. J., FOŘT, T., BURŠíKOVÁ, V. Study of mechanical properties of nanolayered Ti/Ni coatings. In: NANOCON 2017: 9th International Conference on Nanomaterials - Research \& Application. Ostrava: TANGER, 2017, pp. 836-841.

[13] YANG, Z., WANG, J. Temperature and Thickness Dependent Mechanical Properties of Ti/Ni Multilayer Thin Films. Micro and Nanomechanics. 2016, vol. 5, pp. 41-49.

[14] YANG, Z., WANG, J. Coupled annealing temperature and layer thickness effect on strengthening mechanisms of Ti/Ni multilayer thin films. Journal of the Mechanics and Physics of Solids. 2016, vol. 88, pp. 72-82.

[15] CAVAlEIRO, A. J., SANTOS, R.J., RAMOS, A.S., VIEIRA, M.T. In-situ thermal evolution of Ni/Ti multilayer thin films. Intermetallics. 2014, vol. 51, pp. 11-17.

[16] GUPTA, R., GUPTA, M., KULKARNI, S.K., KHARRAZI, S., GUPTA, A., CHAUDHARI, S.M. Thermal stability of nanometer range Ti/Ni multilayers. Thin Solid Films. 2006, vol. 515, 2213-2219

[17] LEHNERT, T., GRIMMER, L., BONI, P., HORISBERGER, M., GOTTHARDT, R. Characterization of shapememory alloy thin films made up from sputter-deposited Ti/Ti multilayers. Acta Materialia. 2000, vol. 48, 40654071. 